TITLE:

\title{
Sexual Difference in Color Sense in a Lycaenid Butterfly, Narathura japonica
}

\section{AUTHOR(S):}

Imafuku, Michio; Shimizu, Isamu; Imai, Hiroo; Shichida, Yoshinori

\section{CITATION:}

Imafuku, Michio ...[et al]. Sexual Difference in Color Sense in a Lycaenid Butterfly, Narathura japonica. Zoological Science 2007, 24(6): 611-613

\section{ISSUE DATE:}

2007-06

URL:

http://hdl.handle.net/2433/85324

RIGHT:

(c) 日本動物学会 / Zoological Society of Japan 


\title{
Sexual Difference in Color Sense in a Lycaenid Butterfly, Narathura japonica
}

\author{
Michio Imafuku ${ }^{1 *}$, Isamu Shimizu ${ }^{2}$, Hiroo Imai ${ }^{3,4}$ and Yoshinori Shichida ${ }^{4}$ \\ ${ }^{1}$ Department of Zoology, Graduate School of Science, Kyoto University, Sakyo, \\ Kyoto 606-8502, Japan \\ ${ }^{2}$ Center for Ecological Research, Kyoto University, 2-509-3 Hirano, \\ Ôtsu, Shiga 520-2113, Japan \\ ${ }^{3}$ Primate Research Institute, Kyoto University, \\ Inuyama 484-8506, Japan \\ ${ }^{4}$ Department of Biophysics, Graduate School of Science, \\ Kyoto University, Sakyo, Kyoto 606-8502, Japan
}

\begin{abstract}
The spectral sensitivity of a lycaenid butterfly, Narathura japonica, was investigated by electroretinography using an integrating sphere that could illuminate the compound eye from almost all directions. Samples were collected from three locations. Butterflies from different locations showed a similar pattern; the first, second, and third peaks (or a shoulder) were located at about 380,460 , and $560 \mathrm{~nm}$, respectively. Males clearly showed the highest sensitivity at the first peak point. In contrast, females showed a higher relative sensitivity than males at the second and third peak points in all samples, and showed broad spectral sensitivity. This male-specific UV-sensitivity is discussed in terms of ecological factors.
\end{abstract}

Key words: color sense, sexual difference, Narathura japonica, ERG, integrating sphere

\section{INTRODUCTION}

Behavioral studies have demonstrated that butterflies, with the most conspicuous and colorful wings of all insects, perceive color (Kühn and Ilse, 1925; Ilse, 1928). Electroretinography (ERG) (Struwe, 1972a; Eguchi et al., 1982) and the analysis of single receptor cells (Struwe, 1972b; Arikawa et al., 1987) have also pointed to the existence of color vision in butterflies. Recently, measurement of single receptor cells (Arikawa et al., 2005) and tapetal reflection (Bernard and Remington, 1991) revealed a sexual difference in color sense.

In some species of butterflies, wing color is associated with color sense. Swihart (1967) measured the response from the medulla interna and obtained a higher response in long wavelengths for Heliconius erato, with a large red band on the forewing, and in short wavelengths for Morpho peleides, with iridescent blue in the central areas of wings. When the response was analyzed at the level of sensory cells based on ERG, there was no such association, but a tendency to show a similar response pattern within a family group was noticed; e.g., lycaenid bluish Pseudozizeeria maha and reddish Lycaena phlaea both showed a purplesensitive pattern (Eguchi et al., 1982). Bernard and Remington (1991), however, found a correlation between wing color and visual pigments for two lycaenid species;

\footnotetext{
* Corresponding author. Phone: +81-75-753-4073; Fax : +81-75-753-4113; E-mail: ima@ethol.zool.kyoto-u.ac.jp
}

Lycaena heteronea with dorsally bluish wings has tetrachromatic sensory receptors including blue receptors, whereas $L$. rubidus with red-orange plus ultraviolet wings has a trichromatic system lacking blue receptors.

Most of the previous investigations were performed on a limited area of the compound eye illuminated with a beam or parallel light (Swihart, 1967; Eguchi et al., 1982), or examined over 10 to 20 ommatidia (Bernard and Remington, 1991). Different types of receptor cells responsible for color sense are unevenly distributed over the compound eye (Bernard and Remington, 1991), and thus spectral sensitivity curves derived from different areas of a compound eye are not the same (Arikawa et al., 1987). To investigate the response from all the color sense receptors on a compound eye, we employed an integrating sphere that could illuminate the compound eye from almost all directions. The lycaenid butterfly Narathura japonica was investigated, because the reflectance of the wing surface of this species was previously determined (Imafuku et al., 2002). We also paid attention to the sexual difference that we found in our first sample, and extended our analysis to other samples collected from different locations for further reconfirmation.

\section{MATERIALS AND METHODS}

\section{Butterflies}

The butterfly Narathura japonica, belonging to Theclinae, Lycaenidae, with a large purple to deep-blue patch on the upper side of the wing, was examined. The underside of the wing was grayish dark brown. Specimens were collected from three locations: Kôchi and Ino Cities (13 females and 6 males, within a 12 km range, 
Kôchi samples) in March 2005; Nakahechi Town, Tanabe City in Wakayama Pref. (11 females and 12 males, $5 \mathrm{~km}$, Tanabe samples) in April 2005; and Ôtsu and Kyoto Cities (10 females and 9 males, 15 km, Ôtsu samples) from October to November 2005. These locations were 140-270 km apart.

\section{Methods}

A specimen whose wings and appendages were removed was fixed on a stage with a compound eye, usually of the right side, facing the top in a Faraday cage. The eye was pierced at the center with a fine needle to make a hole through which an active tungsten electrode (M.T. Giken) was inserted to a depth of ca. $300 \mu \mathrm{m}$ (the thickness of the retina at the center was 330-390 $\mu \mathrm{m}$, determined by sectioning). The indifferent tungsten electrode was inserted in the head at a site other than the compound eyes. The eye to be tested was centered in the opening (1 cm in diameter) of the integrating sphere $(5 \mathrm{~cm}$ in diameter, lined with a sheet of magnesium sulfate powder, Sanso), so as to illuminate the entire eye surface.

Stimulation light was introduced into the integrating sphere through a UV-penetrating liquid fiber. The other end of the fiber was illuminated with a parallel light from a 500-W xenon lamp, after penetrating an interference filter, a neutral density filter, and a wedge filter (Sanso), the last filter adjusting the light intensity of different wavelengths to a fixed level of photons, $1.4 \times 10^{12}$ photons $/ \mathrm{cm}^{2} / \mathrm{s}$. After at least $10 \mathrm{~min}$ of dark adaptation (Eguchi et al., 1982), the compound eye was stimulated with a series of monochromatic light flashes $(60 \mathrm{~ms})$ of $300-700 \mathrm{~nm}$ wavelength at intervals of $20 \mathrm{~nm}$ in turn, with an interstimulus interval of $3.5 \mathrm{~s}$, first from short to long wavelengths and then in the reverse order, and responses from both processes were averaged. The response to white light was taken at several light intensities from $8.2 \times 10^{-3}$ to $2.6 \times 10^{3} \mu \mathrm{W}$ at intervals of 0.5 log unit to obtain a V-logl curve with which a spectral response curve was converted to a spectral sensitivity curve (Eguchi, 2004). The converted sensitivity curve was normalized to the maximum sensitivity as one and expressed as relative sensitivity at each spectral point.

Light intensity was measured with a photo sensor (S1226-5PQ, Hamamatsu Photonics) for relative values of different wavelengths, and a radiometer (USR-40V, Ushio) for absolute values.

\section{Statistics}

For comparison of spectral sensitivity between sexes, we applied the Mann-Whitney $U$ test, using StatView version 5.0 software (SAS Institute).

\section{RESULTS}

Butterflies from the three locations showed a similar relative sensitivity pattern, with the first peak at about $380 \mathrm{~nm}$, the second peak at about $460 \mathrm{~nm}$, and the third peak or a shoulder at around $560 \mathrm{~nm}$ (Fig. 1).

Judging from the sensitivity values, males clearly showed the highest sensitivity to UV light at the first peak point in all samples (Table 1). As indicated by the $p$ value in Fig. 1, females tended to show higher relative sensitivity than males at the second and the third peaks. In some female populations, the sensitivity at the second point was higher than that at the first point, which was not seen in the male populations. These results clearly demonstrate a difference in spectral sensitivity pattern between males and females of a lycaenid butterfly, Narathura japonica.
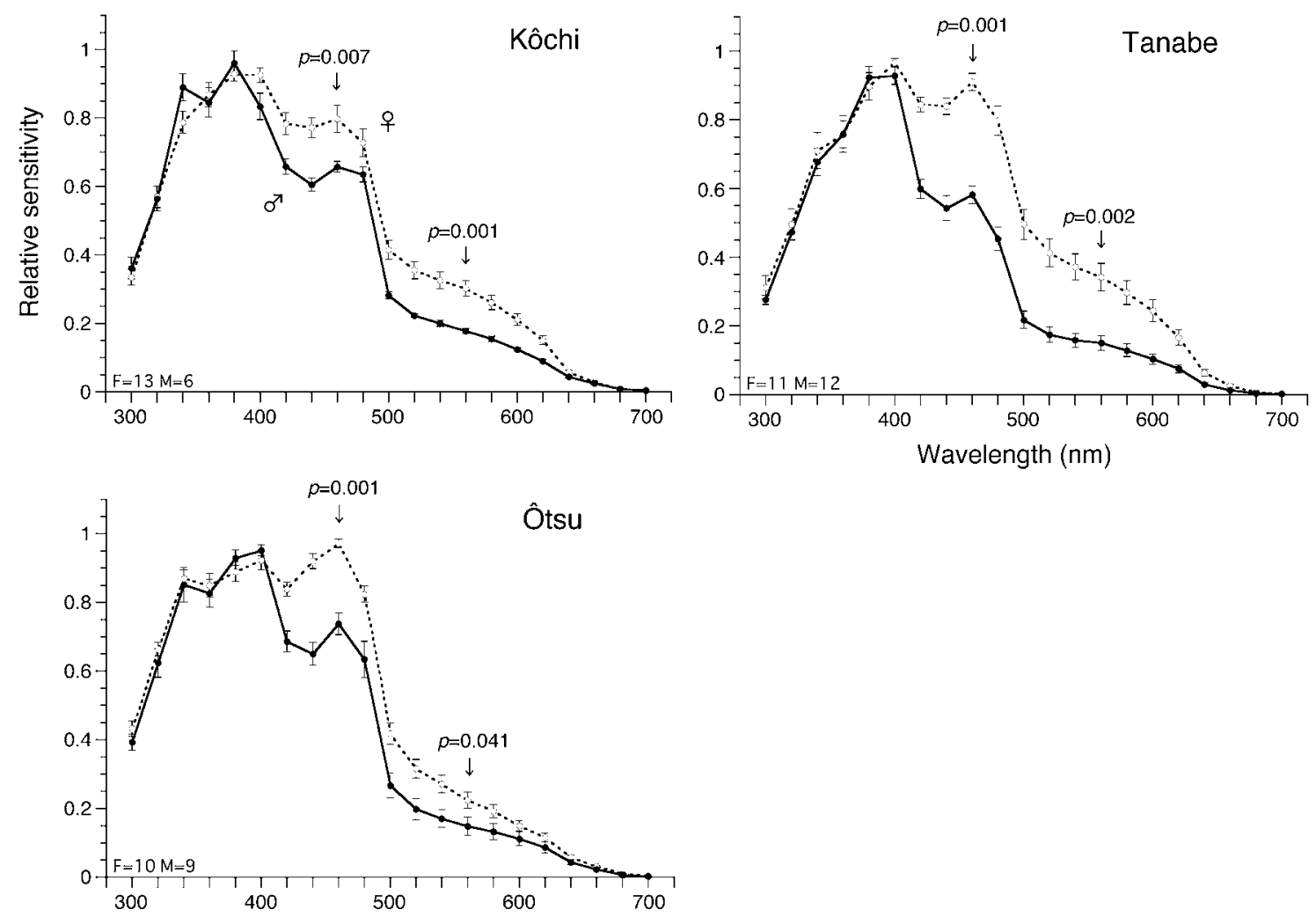

Fig. 1. Relative spectral sensitivity of Narathura japonica from three locations (solid lines, males; dotted lines, females). Vertical bars indicate SEs. Arrows show the wavelength of a second or third peak, or of a shoulder, and the $p$ value near each arrow indicates the level of statistical difference in the relative sensitivity between the sexes. Sample sizes of females (F) and males $(M)$ are shown in the left bottom corner. 
Table 1. Comparison of sensitivity between the sexes. Means \pm SEs (photons $/ \mathrm{cm}^{2} / \mathrm{s}$ ) and $\mathrm{p}$ values are given.

\begin{tabular}{lrrrr}
\hline & & Female & \multicolumn{1}{c}{ Male } & p value \\
\hline Kôchi & & & & \\
& $380 \mathrm{~nm}$ & $96 \pm 5$ & $121 \pm 2$ & 0.023 \\
& $460 \mathrm{~nm}$ & $83 \pm 5$ & $83 \pm 3$ & 0.861 \\
& $560 \mathrm{~nm}$ & $30 \pm 1$ & $23 \pm 1$ & 0.011 \\
Tanabe & & & & \\
& $380 \mathrm{~nm}$ & $84 \pm 5$ & $173 \pm 23$ & 0.001 \\
& $460 \mathrm{~nm}$ & $88 \pm 9$ & $104 \pm 10$ & 0.056 \\
& $560 \mathrm{~nm}$ & $30 \pm 2$ & $24 \pm 2$ & 0.065 \\
Ôtsu & & & & \\
& $380 \mathrm{~nm}$ & $115 \pm 11$ & $165 \pm 21$ & 0.034 \\
& $460 \mathrm{~nm}$ & $126 \pm 11$ & $128 \pm 14$ & 0.744 \\
& $560 \mathrm{~nm}$ & $29 \pm 4$ & $23 \pm 3$ & 0.079 \\
\hline
\end{tabular}

\section{DISCUSSION}

In Narathura japonica, peaks (or a shoulder) of spectral sensitivity were located at about 380, 460, and $560 \mathrm{~nm}$ wavelengths. These points approximately correspond to known visual pigments for lycaenid (P360, P500, and P568; Barnard and Lemington, 1991) and papilionid (360 [PxUV], 460 [PxB], and 575 [PxL3]; Arikawa et al., 2005) butterflies.

Narathura japonica showed a sexual difference; males had a significantly higher sensitivity in the UV light region, as shown in Table 1. A sexual difference is also known in other species. In the dorsal eye region of Lycaena hetero$n e a$ and $L$. rubidus, females showed a trichromatic pattern involving yellow-sensitive pigments (P568), but males showed a dichromatic pattern without them (Barnard and Lemington, 1991). In Pieris rapae, blue photoreceptors of only males were furnished with a filter pigment that caused a slight peak shift to the longer wavelength side (Arikawa et al., 2005). In N. japonicus, the sexual difference seems to be caused by a difference in the number of receptor cells involved, because the peak heights were different at the same peak position; however, a cellular-level analysis is needed before a conclusion can be drawn.

The first peak position of spectral sensitivity function in $N$. japonica roughly matches that of the spectral reflectance from the dorsal surface of the wings of this species; the reflectance peak was at $370 \mathrm{~nm}$ for males and at $400 \mathrm{~nm}$ for females (Imafuku et al., 2002). Thus, males seem to be more sensitive to conspecific wing color, a result well corresponding to that of a behavioral experiment made by Silberglied (1984) in which nymphalid (Anartia amathea) males chose orange-colored females and avoided artificially blackened ones, in contrast to females, who indiscriminately copulated with blackened males as well as red-colored males. A higher spectral sensitivity to conspecific wing color by males seems logical, because the aim of adult males is to acquire conspecific females, whereas that of females is not always to copulate with males but to lay eggs on an appropriate bud of the larval food plant. However, it is premature to draw such a conclusion based on ecological factors, because many lycaenid species are known to show higher sensitivity to UV or blue light (Eguchi et al., 1982), just as seen in our species. Further investigation is needed, extending to more species with different wing colors.

\section{ACKNOWLEDGMENTS}

We heartily thank Kentaro Arikawa of The Graduate University for Advanced Studies, who provided us with the idea for the present study and advice on the basic method. Thanks are also due to Kaoru Tsuji for assistance in ERG measurement, Akira Nagatani for help in the adjustment of instruments, and Akihisa Terakita and Keisuke Sakurai for valuable discussions. This work was supported by a Grant for Biodiversity Research from the 21st Century COE (A14).

\section{REFERENCES}

Arikawa K, Inokuma K, Eguchi E (1987) Pentachromatic visual system in a butterfly. Naturwissenschaften 74: 297-298

Arikawa K, Wakakuwa M, Qu X, Kurasawa M, Stavenga DG (2005) Sexual dimorphism of short-wavelength photoreceptors in the small white butterfly, Pieris rapae crucivora. J Neurosci 25: 5935-5942

Bernard GD, Remington CL (1991) Color vision in Lycaena butterflies: spectral tuning of receptor arrays in relation to behavioral ecology. Proc Natl Acad Sci USA 88: 2783-2787

Eguchi E (2004) Basis of Vision Physiology. Uchida Rokakuho, Tokyo (In Japanese)

Eguchi E, Watanabe K, Hariyama T, Yamamoto K (1982) A comparison of electrophysiologically determined spectral responses in 35 species of Lepidoptera. J Insect Physiol 28: 675-682

Ilse D (1928) Über den Farbensinn der Tagfalter. Z Vergl Physiol 8: 658-692

Imafuku M, Gotoh S, Takeuchi T (2002) Ultraviolet reflection by the male of Narathura bazalus (Lycaenidae). Trans Lepid Soc Japan 53: 197-203

Kühn A, Ilse D (1925) Die Anlockung von Tagfaltern durch Pigmentfarben. Biol Zbl: 144-149

Silberglied RE (1984) Visual communication and sexual selection among butterflies. In "Biology of Butterflies" Ed by RI VaneWright, PR Ackery, Academic Press, London, pp 207-223

Struwe G (1972a) Spectral sensitivity of the compound eye in butterflies (Heliconius). J Comp Physiol 79: 191-196

Struwe G (1972b) Spectral sensitivity of single photoreceptors in the compound eye of a tropical butterfly (Heliconius numata). J Comp Physiol 79: 197-201

Swihart SL (1967) Neural adaptations in the visual pathway of certain heliconiine butterflies, and related forms, to variations in wing coloration. Zoologica 52: 1-14

(Received September 28, 2006 / Accepted January 26, 2007) 